\title{
O genograma e o ecomapa no cuidado de enfermagem em saúde da família
}

\author{
The genogram and the eco-map in family health nursing care \\ El genograma y el ecomapa en la atención de enfermería en la salud de la familia
}

\section{Amanda Priscila de Souza Pereira', Graziella Martins Teixeira', Carolina de Araújo Belcorso Bressan', Jussara Gue Martini'}

'Universidade Federal de Santa Catarina. Departamento de Enfermagem, Grupo de Assistência, Pesquisa e Educação na Área da Saúde da Família. Florianópolis, SC

Submissão: $01 / 11 / 2008$

Aprovação: 29/05/2009

\begin{abstract}
RESUMO
A enfermagem precisa observar a importância da família, pois se está presente e orientada para cuidar, contribui mais efetivamente para uma vida saudável de seus membros. O estudo objetivou conhecer as formas de enfrentamento de seis famílias com agravos crônicos, através de três visitas domiciliares, fazendo uso de entrevista, ficha de identificação, genograma e ecomapa. De um modo geral, as famílias enfrentam satisfatoriamente os agravos crônicos e situações estressoras. Foi preciso cumprir a difícil tarefa de exercitar a visão ampliada, exigida do enfermeiro, para compreender Que o processo de trabalho não se restringe a atuação sobre doenças e agravos, mas dar condições a família para con̨uistarem a saúde em todas as suas dimensões.
\end{abstract}

Descritores: Família; ; Visita Domiciliar; Saúde pública; Enfermagem.

\section{ABSTRACT}

The nursing needs to observe the importance of the family, because if the family is presentand oriented for cared, it contributes more effectively to the healthy life of its members. The study aimed at learning the coping behaviour of six families with chronic diseases, through three home visits, using interviews, form of identification, genogram and eco-map. In general, families face satisfactorily the chronic stress situations. It was needed to forfill the difficult task of exercising the broader view, required the nurse to understand that the process of work is not restricted to acting on diseases and disorders, but give the family conditions to earn health in all its dimensions.

Descriptors: Family; Home visit; Public health; Nursing.

\section{RESUMEN}

La enferermeía precisa observar la importancia de la familia, poreue cuando ella esta presente orienta y cuida a la familia, contribuyendo con mas eficacia a la salud de sus miembros. El estudio se enfoco en la manera de aprender a afrontar la lucha de seis familias con enfermedades cronicas, con tres visitas caseras, usando entrevistas, una forma de identificacion del genograma y del ecomapa. Las familias se enfrentan satisfactoriamente a los agravos cronicos y situaciones de estres. Fue necesario cumplir la dificil tarea de ejercitar una vision ampliada, exigida por la enfermera, para comprender Que el proceso del trabajo no se restringe a actuaciones sobre desordenes o agravos, sino dar a la familia condiciones para ganar salud en todas sus dimensiones.

Descriptores: Família; Visita domiciliaria; Salud pública; Enfermería. 


\section{INTRODUÇÃO}

A Política Nacional de Atenção Básica(l) descreve o processo de trabalho das equipes de saúde da família orientando a prática para o "cuidado familiar ampliado, efetivado por meio do conhecimento da estrutura e da funcionalidade das famílias Que visa propor intervenções Que influenciem os processos de saúde-doença dos indivíduos, das famílias e da própria comunidade".

As experiências acadêmicas na prática assistencial nas Unidades Locais de Saúde ainda dizem respeito ao cuidado ao indivíduo, atuando principalmente para a recuperação da saúde, em menor escala à prevenção de agravos e de forma muito incipiente à promoção de saúde.

Concordamos com grandes autores, como Althoff et $\mathrm{a}^{(2)} \mathrm{e}$ Elsen e Althoff( ${ }^{(3)}$, e organizações, como o Ministério da Saúde, Quando afirmam que é na Atenção Básica Que se encontra a possibilidade de vínculo entre a comunidade e os profissionais, formando elos de confiança e co-responsabilidade, o Que possibilita uma melhor atuação profissional. Por acreditar que esta possibilidade de vínculo pode ser explorada de forma mais intensa, elegemos a família como foco principal do nosso estudo.

Uma família presente e orientada para o cuidado poderá atuar de forma muito mais resolutiva para a recuperação da saúde e prevenção de doenças de seus pares, além disso, sua participação na promoção da saúde se torna fundamental uma vez Que os componentes da família passam a ser co-responsáveis pela vida e saúde uns dos outros.

Apesar do grande volume de pesquisas na área da família é ainda necessário investigar, pois atuar nesta área torna-se um desafio pela sua complexidade, o Que nos impulsiona a buscar novos aspectos e a aprimorar nossa prática assistencial ${ }^{(2)}$.

Então, reconhecendo Que a família influencia a vida de seus indivíduos, percebendo as diversidades culturais existentes, decidimos atuar e pesquisar neste âmbito, onde pesquisadoras ${ }^{(3)}$ enfatizam a família, como foco central na pesQuisa, está cercada por avanços teóricos e metodológicos, porém ainda insuficientes, se considerarmos a sua complexidade e multidimensionalidade.

Para focalizar o estudo limitamos nossa atuação em famílias onde pelo menos um dos membros era portador de Hipertensão Arterial Sistêmica (HAS) e Diabetes Mellitus (DM). A cronicidade desses agravos e o grande impacto Que trazem para o perfil de morbimortalidade brasileira evidenciam um desafio para o sistema público brasileiro, principalmente na atenção básica, pois é neste âmbito Que é garantido o acompanhamento sistemático das famílias com agravos crônicos, bem como o desenvolvimento de ações referentes à promoção de saúde e a sua prevenção. Vale ressaltar Que no campo da promoção da saúde e redução de fatores de risco os serviços de saúde oferecidos neste campo são ínfimos e críticos pela falta de tradição na realização sistemática destas ações ${ }^{(4)}$. Somando-se as razões de escolha desses agravos, Zanetti et $\mathrm{al}^{(5)}$, afirmam Que a abordagem para o gerenciamento de doença crônica baseada na família pode ser considerada um acréscimo às estratégias de tratamento convencionais.

$\mathrm{O}$ estudo objetivou conhecer as formas de enfrentamento desenvolvidas por famílias de pessoas Que vivem com HAS e DM, na área de abrangência da Unidade Local de Saúde (ULS) da Lagoa da Conceição em Florianópolis.

\section{METODOLOGIA}

Foi utilizado como referencial metodológico a Pesquisa Convergente Assistencial ${ }^{(6)}$, uma modalidade de pesquisa que durante todo o seu processo mantém íntima relação com a prática assistencial, com o objetivo de encontrar meios para resolver ou minimizar problemas, realizar mudanças e introduzir e melhorar as formas de realização da prática.

Como marco teórico foi utilizado o Modelo Interativo do Estresse de Folkman et $\mathrm{al}^{(7)}$. A assistência prestada foi embasada na Teoria da Universalidade e da Diversidade do Cuidado Cultural de Leininger, e assim como Marcon e seus colaboradores ${ }^{(8)}$ no relato de suas atividades com famílias de pacientes crônicos, visamos os indivíduos e suas famílias, oferecendo-lhes apoio, orientações, e assistência à saúde voltada para adoção de novos hábitos de vida, tendo em vista a promoção a saúde da família. E também ajudando a perceberem e sanarem suas dúvidas relacionadas à saúde e ao cuidado recebido, almejando sua capacidade para se autocuidar.

A pesquisa foi desenvolvida na ULS da Lagoa da Conceição na cidade de Florianópolis. A ULS tem sua área de abrangência dividida em duas áreas compostas por sete microáreas cada uma, com total de 8.074 habitantes, segundo o Censo Demográfico do IBGE de 2000 , com projeção para $2007^{(9)}$. Utilizamos o espaço físico da ULS para realização de reuniões e consultas de enfermagem, Quando necessárias, e principalmente a residência das famílias pesQuisadas.

Participaram do estudo seis famílias em Que há a situação de agravos crônicos (DM e/ou HAS), sendo três famílias onde o portador do agravo crônico mora sozinho ou apenas com o companheiro e três famílias onde os filhos moram com o portador. O portador deveria ter mais de 50 anos de idade.

A seleção das famílias ocorreu por indicação dos agentes comunitários de saúde e da nossa participação no Grupo Floripa Ativa $^{a}$, onde se destacam famílias com maior vulnerabilidade na situação de enfrentamento dos agravos crônicos.

As visitas domiciliares (VD) aconteceram durante o primeiro semestre de 2008 e tiveram duração média de 60 minutos cada uma. Na primeira VD foram apresentados os aspectos éticos e legais para realização de pesQuisa com seres humanos e realização da entrevista semi-estrutura objetivando a aproximação com as famílias. Sendo Que esses dados serviram como base para a construção de práticas educativas e assistenciais nos encontros posteriores, visando à melhoria da Qualidade de vida e à promoção da saúde. lá na segunda visita houve o esclarecimento de dúvidas levantadas a partir do primeiro encontro, orientações e cuidados e construção do genograma e ecomapa. E na terceira e última visita, a realização de orientações voltadas para dieta alimentar adeQuada, uso correto de medicações, entre outros, dependendo das necessidades e demandas de cada família, e a despedida.

A inclusão das famílias em nossa pesQuisa obedeceu à Resolução no 196/96 do Conselho Nacional de Saúde do Ministério da Saúde, Que dispõe sobre diretrizes e normas regulamentares da pesQuisa

\footnotetext{
a $O$ grupo de educação em saúde e reabilitação física, Floripa Ativa é a fusão dos programas Floripa em Forma, Que visa à reabilitação cardiopulmonar e metabólica, Idoso Ativo e Viver Ativo, Que são programas de prevenção de agravos e promoção da saúde. A participação no grupo Floripa Ativa tem como critério ser idoso e apresentar comorbidades pulmonares ou cardiovasculares ${ }^{(8)}$.
} 
envolvendo seres humanos. O projeto para esta pesquisa foi aprovado pelo Comitê de Ética de Pesquisas em Seres Humanos da Universidade Federal de Santa Catarina, sob o parecer no 042/ 2008. Com relação à autorização dos sujeitos da pesQuisa, a mesma foi obtida através do Termo de Consentimento Livre e Esclarecido (TCLE), assinado pelo portador de agravo crônico e garantindo a todas as famílias a liberdade de participarem ou não e de desistirem a QualQuer momento, sem QualQuer prejuízo na assistência Que recebem na instituição. Também foram assegurados o sigilo e o anonimato, utilizando numerais e iniciais dos nomes.

Os dados foram obtidos através de alguns instrumentos: a entrevista semi-estruturada, a construção do genograma e ecomapa com os membros da família e também a observação participativa nas três visitas domiciliares a cada família.

O genograma e o ecomapa são instrumentos Que facilitam a avaliação da estrutura familiar. Através deles é possível ter uma rápida visão da complexidade das relações familiares e são ricas fontes de informação, de forma sucinta, para o planejamento de estratégias ${ }^{(10)}$. A construção destes dois instrumentos fica mais rica e retratam a família de forma mais detalhada Quando são feitos juntamente com a família e o enfermeiro ${ }^{(1)}$.

O genograma demonstra a representação gráfica de dados sobre a família, e durante a sua construção há a visualização da dinâmica familiar e as relações entre seus membros, através de símbolos e códigos padronizados, em pelo menos três gerações. Para construção dos genogramas com as famílias foi preciso definir uma pessoa de origem, Que denominamos usuário índice, para tomarmos como ponto referência para as relações interpessoais familiares e geracionais de ascendência e descendência. Desde modo, elegemos usuário índice o portador de agravo crônico Que também assinou o TCLE, assumindo a co-responsabilidade da família conosco.

O genograma permite, também, observar de uma forma clara Quais membros constituem a família, tenham eles vínculos consangüíneos ou não, desta forma, fornece bases para a discussão e análise das interações familiares. Os homens são representados por Quadrados e as mulheres por círculos, identificando o nome, a idade, a profissão e doenças atuais de cada pessoa, além de retratar o lugar ocupado por cada um dentro da estrutura familiar ${ }^{(12)}$. Também faz com Que a própria família identifieue Quais os membros Que a integram, as relações estabelecidas entre $\mathrm{si}^{(13)}$.

O ecomapa é um diagrama das relações entre a família e a comunidade que ajuda a avaliar as redes e apoios sociais disponíveis e sua utilização pela família. Contendo os contatos das famílias com pessoas, instituições ou grupos. Representando ausência ou presença de recursos sociais, culturais e econômicos, de um determinado momento do ciclo vital da família, havendo modificação ao longo do tempo, portanto dinâmico. Uma família Que tem poucas conexões com a comunidade necessita maior investimento da enfermagem em intervenções Que auxiliam na busca por mais conexões ou estabilizações das relações ${ }^{(14)}$.

No ecomapa os membros da família são representados no centro do círculo. Já a rede social da família aparece em círculos externos. As linhas indicam o tipo de conexão: linhas contínuas representam ligações fortes, pontilhadas ligações frágeis, linhas tortuosas demonstram aspectos estressantes e as setas significam energia e fluxo de recursos ${ }^{(13)}$.

Os dados foram analisados através da Análise de Conteúdo Que significa um conjunto de técnicas de análise de comunicação Que tem por finalidade a compreensão de conteúdos manifestos e ocultos ao organizar os dados em palavras significativas ou categorias, classes de dados definidos por uma expressão ou palavras ${ }^{(15)}$.

\section{RESULTADOS E DISCUSSÃO}

Para caracterizar as famílias pesquisadas, realizamos o preenchimento de um Formulário de Identificação da Família, a partir dela, coletamos os seguintes dados.

As seis famílias eram constituídas por casais (3), casal e filho (1), casal e netos (1), e casal, filhos, neto, cunhada e sobrinho (1). No total assistimos vinte e uma pessoas, treze do sexo masculino com idade entre um e oitenta e três anos (criança, adolescente, adulto jovens, adultos maduros e idosos) e oito do sexo feminino entre vinte e Quatro e setenta e nove anos (adulta jovem, adultas maduras e idosas). Quanto à religião, cinco famílias eram católicas e uma evangélica.

A renda familiar variou de 4 a 10 salários míninos, com contribuição apenas do homem chefe da família (2), do casal (2), do casal e do filho ( I), do casal e da cunhada (1). As moradias são casas próprias, com exceção de uma família Que reside em apartamento próprio.

No item profissão, vê-se o predomínio de servidores públicos (7), estudantes (5) e mulheres donas de casa (3), mas também há trabalhador de serviços gerais (1), fazendeiro (1), zelador (1), garçom (1), trabalhadora autônoma (1) e comerciário (1). De todos, cinco são aposentados por tempo de serviço, idade ou invalidez.

Todos utilizam o Sistema Único de Saúde, tendo a ULS Lagoa da Conceição como referência na Atenção Básica e convênios privados. Apenas duas famílias declararam atendimento particular em saúde.

Para poder averiguar, sugerir e orientar formas de cuidados focalizados, nós os Questionamos sobre a situação de doenças da família. Além da presença de DM e HAS, critérios de inclusão nesta pesquisa, observamos na família nuclear a presença de cardiopatias, acidente vascular cerebral, isquemia vascular cerebral, infarto agudo do miocárdio, labirintite, enxaqueca, hipercolesterolemia, gastrite, problemas na coluna, fratura de fêmur, costelas e braço, divertículos, artrose, tendinite, fibromialgia, diminuição da acuidade visual e auditiva.

Uma família declara não ter nenhuma forma de lazer, entretanto as outras relatam várias atividades Que realizam com freqüência, como ouvir música, dormir, namorar, dançar, caminhar à beira da Lagoa, pescar, participar de jogos coletivos (futebol, dominó, bingo), participar das atividades da igreja, realizar passeios e viagens.

A participação em grupos de educação em saúde e de convivência também foi Questionada, três famílias não participam de nenhum grupo, duas famílias participam apenas do grupo Floripa Ativa, e uma participa do Floripa Ativa e de mais dois grupos de idosos.

Ainda faziam parte do Formulário os itens endereço, estado civil, escolaridade, saneamento básico.

Foi necessária a conceituação de família nuclear e ampliada para explicitar o nosso foco de pesquisa e assistência e também foi indispensável para a construção do genograma e ecomapa juntamente com a família.

A família nuclear tradicionalmente é constituída pelo trinômio 
pai-mãe-filhos, podendo ser ampliada com a inclusão dos parentes mais próximos ou pessoas Que a família considere integrantes deste sistema $^{(16)}$. Para operacionalizar esta pesquisa, restringimos família nuclear ao grupo domiciliar, ou seja, aos indivíduos Que se considerem família e Que residem sob o mesmo teto ${ }^{(17)}$.

lá a família ampliada ou consangüínea é composta pela família nuclear Que se soma a outros parentes diretos ou colaterais, ou seja, pessoas Que tenham laços de parentesco e também os não parentes Que coabitem ${ }^{(18)}$.

Citaremos genogramas e ecopamas de duas famílias Que se destacaram por suas peculiaridades, a Família 4 pelas suas várias formas de enfrentamento e a Família 6 pela sua conformação e relações interfamiliares.

No genograma da Família 4 (Apêndice A) a usuária índice é a I.S.T., com 56 anos, secretária do Núcleo de Educação Infantil e é portadora de HAS, DM, fibromialgia e tendinite. É casada com A. I. T., representado pela linha contínua Que liga o casal. Os irmãos do casal aparecem somente de forma ilustrativa, representados por losangos Que significam sexo não especificado. E os números no centro são a Quantidade de irmãos (mais novos à direita e mais velhos à esquerda). Sendo o casal a família nuclear, estando dentro do espaço limitado por uma linha Que engloba ambos, representando os membros pesquisados. Acima do casal são descritos seus ascendentes, observamos Que a maioria deles são falecidos, representados por um $X$, tendo a idade ao falecer e a sua causa sublinhada, e abaixo seus descendentes, os filhos que se originam da linha contínua do casal. Outro requisito para construir o genograma é ter no mínimo três gerações, neste genograma há Quatro gerações: os pais, o casal, filhos e netos, o Que possibilita também demonstrações das doenças hereditárias.

A nossa usuária índice tem relações muito próximas com seu marido e seu neto, descritas pelas linhas Que descrevem as relações interpessoais, com três linhas paralelas; e com os outros membros ela mantém relações próximas, com duas linhas paralelas.

O ecomapa pode conter contatos com grupos variados, assim no ecomapa da Família 4 (Apêndice A) há contatos com pessoas (família ampliada, vizinhos e amigos íntimos), instituições (ULS, igreja,) e grupos (Floripa Ativa, idosos).

As linhas significam as relações, como no genograma. As relações muito próximas, representadas por três linhas paralelas (família ampliada e grupo Floripa Ativa), próximas por duas linhas (vizinhos e o trabalho), distantes, por linhas pontilhadas (escola dos netos e a Família 4 aQui considerou relações distantes com a ULS, pois se referiram a sua relações interpessoal com os profissionais, mas tem a unidade como referência de serviço de saúde). E as setas representam energia e fluxo de recursos Que podem ou não originar de ambas as partes. A família nuclear tem um suporte social muito atuante, com fluxo e energia recíprocos.

Ao comparar-se o genograma anterior com o da Família 6 (Apêndice B), percebe-se Que sua conformação e suas relações familiares são muito mais complexas. A usuária índice M.M.V., tem 65 anos, é do lar e tem HAS e osteoporose. É casada com I.H.V e observa-se Que ambos já foram casados. A usuária índice é viúva do primeiro marido e teve Quatro filhos com ele. Seu marido atual é divorciado, representado por essas duas linhas que cortam a linha do casamento, e adotaram uma filha, descrita pela letra "A", mas já é falecida. $\mathrm{O}$ casal não tem filhos. Fazendo parte também da família nuclear dois netos da MMV, destacando Que ambos estão dentro do limite da linha que representa a família nuclear. Observam-se algumas diferenças das situações conjugais da família anterior. Havendo vários exemplos nas relações conjugais de seus filhos. As linhas pontilhadas representam Que moraram juntos e não se casaram, e apenas uma linha Que cruza as linhas pontilhadas significa Que se separaram. Além das relações muito próximas e próximas, observam-se linhas tortuosas, Que significam conflitos. Aqui essas relações não são ligadas a usuária índice, mas influenciam sua vida. Como a relação conflituosa de seu marido com a ex-esposa e de sua neta com a atual companheira de sue filho.

No ecomapa desta família (Apendice B), encontram-se diferenças do ecomapa da Família 4. Havendo relações conflituosas com alguns vizinhos e também muito próximas com outros. E comparando-se as seis famílias do estudo, apenas esta não mantém relações com alguns instrumentos de sua rede social, confirmando-se pela ausência de linhas. E afirmadas pela família Que esta ausência de relações interfere negativamente em suas vidas. Não há relações desta família com locais Que proporcionam lazer, sendo mais um fator agravante para o enfrentamento de suas doenças.

Analisamos os dados obtidos com base no Modelo Interativo do Estresse de Folkman et $\mathrm{al}^{(7)}$, o Qual descreve as estratégias de enfrentamento, Que podem ser focalizadas no problema ou na emoção. Quando o foco está no problema há gerenciamento ou alteração da situação estressora, com intuito de controlá-la, levando em alguns casos, a solução do problema. No segundo tipo de estratégia, Quando o foco está na resposta emocional causada pelo problema, há a possibilidade de controlar, reduzir ou eliminar as respostas emocionais, sendo uma forma paliativa de enfrentamento, uma vez Que o indivíduo tenta minimizar o estresse, sentindo-se melhor diante de uma situação estressora presente. Dentre as formas paliativas incluem-se ainda negação e esquiva ${ }^{(7,19)}$.

Sendo possível relacionar esses dois enfoques:

essas duas formas de enfrentamento são inter-relacionadas, visto Que as pessoas, diante de um mesmo evento estressor, utilizam ambas as formas de enfrentamento, pois uma estratégia Que, em princípio, está focalizada no problema, pode ter também uma função focalizada na emoção e, portanto, a emoção e o enfrentamento ocorrem numa relação dinâmica e recíproca ${ }^{(19)}$.

Os resultados desta pesQuisa apontam a inter-relação ocorrida entre as duas formas de enfrentamento, baseadas na emoção e no problema, confirmando as afirmações citadas acima.

Como principal forma de enfrentamento com vistas às emoções, destacamos Que todas as famílias participantes buscam apoio na própria família, nuclear e ampliada. Tendo ainda este mesmo enfoque, a Família 2 demonstra ótimo relacionamento e união entre o casal, fato Que os torna capazes de partilhar sentimentos e pensamentos.

O suporte social da Família 4 é bem extenso, ressaltamos a importância da participação em grupos de convivência e atividades coletivas como formas de enfrentamento com foco nas emoções. Observamos que o suporte social desta família completa os seus recursos pessoais para enfrentarem novas exigências e atingirem novos objetivos, agindo também como um dos promotores de sua assistência, promovendo bem-estar físico e psicológico.

A realização profissional e a religiosidade são formas de enfrentamento apresentadas pela Família 5, sendo a única família 
pesquisada Que declaram espontaneamente a importância destas para o enfrentamento e para seu viver saudável.

Nas formas de enfrentamento Que enfatizam o problema (agravo crônico e as adversidades da vida) foi possível observar Que todas as famílias buscam auxílio nos serviços de saúde público e privado. Com exceção da Família 3, todas as famílias têm preocupação e seguem dieta alimentar adeQuadamente.

As atividades físicas eram realizadas regularmente por duas famílias, principalmente através do grupo Floripa Ativa. A participação neste grupo apesar de ser uma forma de enfrentamento focalizada no problema por objetivar a recuperação cardiopulmonar, também pode ser enfocada nas emoções, uma vez Que proporciona o convívio social entre os participantes.

O estresse, segundo Lazarus, Folkman e Pargament ${ }^{(7)}$, não é o evento em si, mas a representação das avaliações da situação, ele pode ser avaliado de duas formas: primária e secundária. Inicialmente a pessoa examina a situação vivenciada, podendo classificá-la em potencialmente desafiadora, prejudicial ou ameaçadora. Já na avaliação secundária a pessoa busca em seus próprios recursos formas de enfrentar a situação estressante, através de estratégias para lidar com a mesma: contornando a ameaça ou o dano; ou adQuirindo recompensas a partir de seu enfrentamento ${ }^{(7)}$.

Além da capacidade de restabelecer o estado anterior após uma situação de estresse, resiliência é uma capacidade desenvolvida ao longo do processo de viver humano Que trata da superação da dificuldade enfrentada e da busca de novos rumos a partir deste fato. Ou seja, resiliência pode ser vista como o porquê de, mesmo em situações de adversidades sociais, econômicas e psicológicas, alguns indivíduos conseguirem sobreviver e alcançar o bem-estar em suas vidas, enQuanto outros não o obtinham ${ }^{(20,21)}$.

Em nossa pesquisa pudemos observar principalmente a forma secundária de avaliação de estresse. A forma primária foi constatada apenas na Família 3, Que tem muitas dificuldades e ainda encontrase no estágio inicial de aceitação da situação de agravos crônicos, desenvolvendo formas paliativas de enfrentamento.

Em contrapartida a Família 4 já passou pelas duas formas de avaliação do estresse, vivendo atualmente o estágio de adQuirir recompensas a partir da resiliência através de suas variadas e eficazes formas de enfrentamento.

Ao longo da busca de dados com as famílias surgiram alguns contratempos e constatações Que ao final não prejudicaram os resultados, mas nos incomodaram pela sensação de coresponsabilidade com as famílias.

Aconteceram choques de horários entre as famílias, uma vez Que eram elas Quem os marcavam, foi preciso adaptar as agendas para poder assistir a todas com satisfação e dentro do cronograma pré-estabelecido para a pesquisa.

Após a segunda VD uma das famílias passou a demonstrar desinteresse em relação a nossa visita, desconfiando dos objetivos e seriedade de nosso estudo. As informações éticas e legais foram expressas no momento inicial do convite através dos agentes comunitários de saúde e assinatura da TCLE e reafirmadas a cada encontro. Mesmo com o desinteresse a família não optou por seu desligamento da pesquisa, contribuindo da mesma forma Que as outras famílias para a realização desta investigação.

Devido à limitação do número de visitas previstas, observamos a necessidade de continuidade da assistência a uma das famílias.
Isto poderia ser realizado pela equipe de saúde da família, no entanto, a operacionalização da ESF na Lagoa da Conceição não permite esse acompanhamento mais próximo a todas as famílias.

Finalizando, acreditamos Que, de um modo geral, as famílias enfrentam satisfatoriamente os agravos crônicos e situações estressoras, apresentando maior e menor grau de dificuldade para fazê-lo. Mesmo com as adversidades de viver com a doença e suas complicações, observamos Que as famílias desenvolvem atitudes Que permitem um viver saudável, desempenhando suas atividades Quotidianas de formas culturalmente aceitas.

\section{CONSIDERAÇÕES FINAIS}

Chegando ao fim de mais uma etapa desta pesquisa, não poderíamos deixar de expor nossa experiência com a utilização da Pesquisa Convergente Assistencial, Que nos permitiu Que ao mesmo tempo em Que oferecíamos cuidados pesquisássemos, e deste modo todas as situações e comportamentos observados passaram a ser dados da pesquisa. Foi possível realizar a coleta de dados a partir do envolvimento com as famílias, o Que a tornou dinâmica, interessante e fácil de fazer. Visto a complexidade das famílias os resultados apresentados serão válidos apenas tendo como base a realidade dos sujeitos, sua cultura, seu ambiente, sua época.

Concordando com as autoras desta metodologia de pesquisa ${ }^{(5)}$, acreditamos Que esta só pode ser realizada no contexto da prática assistencial, "pois não se propõe a generalizações, seus objetivos são para descobrir realidades, relacionadas a resoluções de problemas e inovações", deste modo sugerimos aos profissionais de saúde que a utilizem na realização de seus estudos, unindo o saber e o fazer mais facilmente.

A escolha pelos instrumentos genograma e ecomapa permitiu vislumbrar cada família, em sua complexidade e dinamicidade. No entanto, para o processo de trabalho das equipes de saúde da família são instrumentos pouco aplicados, restringindo-se ao uso acadêmico por despenderem tempo para dedicar atenção necessária para construí-los de forma adequada, para sua análise e atuação frente às exigências de cuidados encontradas, e ainda para sua atualização, visto Que é o retrato de um momento do ciclo vital da família, e desta forma, sofre modificações ao longo do processo de viver humano.

A Estratégia de Saúde da Família (ESF) preconiza a visita domiciliar como uma forma de assistência à família em seu ambiente sociocultural, abordando-a de modo integral e individualizado. Ao realizarmos visita domiciliar para assistir às seis famílias e coletar dados para nosso estudo utilizamos a teorista de enfermagem Leininger, Que assim como o Ministério da Saúde, diz que o profissional de saúde, em especial o de enfermagem, deve ter atitudes de respeito e valorização à cultura e às características inerentes a cada família.

A oportunidade de atuar na Atenção Básica permitiu-nos criar elos de confiança e co-responsabilidade com famílias e com a comunidade. Dentro do desenvolvimento desta pesquisa, tal vínculo proporcionou comunicação livre de entraves e garantiu a veemência das informações coletadas.

Acreditamos ter cumprido os objetivos a Que nos propusemos. Ao conhecer as formas de enfrentamento das famílias pudemos constatar Que pessoas e famílias são processos dinâmicos. Foi preciso cumprir a difícil tarefa de exercitar a visão ampliada, exigida do 
profissional enfermeiro, para compreender Que o processo de trabalho não se restringe a atuação sobre doenças e agravos, mas dar condições a pessoa, família e comunidade para alcançarem saúde biológica, psicológica, espiritual, social e ambiental, conhecendo assim Quem são, suas condições de saúde-doença, suas dificuldades e fortalezas, seus valores e ambiente sociocultural.

\section{REFERÊNCIAS}

I. Ministério da Saúde (BR). Portaria n. 648/GM, de 28 de março de 2006. Aprova a Política Nacional de Atenção Básica, estabelecendo a revisão de diretrizes e normas para a organização da Atenção Básica para o Programa Saúde da Família (PSF) e o Programa Agentes Comunitários de Saúde (PACS). Brasília: Ministério da Saúde; 2006. [citado em 25 nov 2007]. Disponível em: http://dtr200I.saude.gov.br/sas/PORTARIAS/ Port2006/GM/GM-648.htm

2. Althoff CR, Fernandes GCM, Scmickler CM, Mioto, RCT. Pesquisando a família: por onde caminham os pesQuisadores. In: Elsen I, Althoff CR, Nitschke RG. Pesquisando a família: olhares contemporâneos. Florianópolis: Papa Livro, 2004, p. 29-42.

3. Elsen I, Althoff CR. Família e pesquisa: os contornos de um universo a explorar. In: Elsen I, Althoff CR, Nitscheke RG. Pesquisando a família: olhares contemporâneos. Florianópolis: Papa Livro, 2004, p. 19-28.

4. Ministério da Saúde (BR). Secretaria de Políticas de Saúde. Plano de reorganização da atenção à hipertensão arterial e ao diabetes mellitus. Brasília: Ministério da Saúde; 2001. [citado em 25 nov 2007]. Disponível em: http://bvsms.saude.gov.br/bvs/ publicacoes/reorganizacao_plano.pdf

5. Zanetti ML, Biagg MV, Santos MA, Peres DS, Teixeira CRS. O cuidado à pessoa diabética e as repercussões na família. Rev Bras Enferm 2008; 6I(2): 186-92.

6. Trentini M, Paim L. Pesquisa convergente assistencial: um desenho Que une o fazer e o pensar na prática assistencial em saúde-enfermagem. Florianópolis: Insular, 2004.

7. Faria JB, Seidl EMF. Religiosidade e enfrentamento em contextos de saúde e doença: revisão da literatura. Psicol Reflexão Crítica 2005; 18(3): 381-9.

8. Marcon SS, Waidman MAP, Carreira L, Decesaro MN Compartilhando a situação de doença: o cotidiano de famílias de pacientes crônicos. In: Elsen I, Marcon SS, Silva MRS, organizadores. O viver em família e sua interface com a saúde e a doença. Maringá: Eduem; 2004. p. 265-81.

9. Prefeitura Municipal de Florianópolis. Secretaria Municipal de Saúde. População 2007. Florianópolis; 2007. [citado em 3 dez 2007]. Disponível em: http://www.pmf.sc.gov.br/saude/ unidades_saude/populacao/uls.php?cod_uls $=$ lag

10. Bousso RS, Angelo M. A enfermagem e o cuidado na saúde da família. In: Ministério da Saúde (BR). Instituto para o Desenvolvimento da Saúde. Universidade de São Paulo. Manual de Enfermagem. São Paulo: IDS; 200 I, p. 18-22.

11. Simpionato E, Correia CC, Rocha SMM. Histórico familiar de crianças com insuficiência renal crônica: coleta de dados. Rev Bras Enferm 2005; 58(6): 682-5.

12. Dias J, Nascimento, LC, Mendes IJM, Rocha, SMM. Promoção de saúde das famílias de docentes de enfermagem: apoio, rede social e papéis na família. Texto Contexto Enferm 2007; 16(4): 688-95.

13. Nascimento LC, Rocha SMM, Hayes VE. Contribuições do genograma e do ecomapa para o estudo de famílias em enfermagem pediátrica. Texto Contexto Enferm 2005; 14(2): 280-6.

14. Rocha SMM, Nascimento LC, Lima RAG. Enfermagem pediátrica e abordagem da família: subsídios para o ensino de graduação. Rev Latino-am Enfermagem 2002; 10(5): 709-14.

15. Cascais AF, Martini JG. A pessoa ostomizada: suas representações corporais e estratégias de enfrentamento. [anteprojeto]. Florianópolis (SC): Curso de Pós-Graduação em Enfermagem, Universidade Federal de Santa Catarina; 2007.

16. Machado HV. Reflexões sobre concepções de família e empresas familiares. Psicol Estudo 2005; 10(2): 317-23.

17. Alves IED. A definição de família convivente do IBGE: cuidados metodológicos necessários. Rio de Janeiro: Universidade Federal do Rio de Janeiro. [citado em 12 jun 2008]. Disponível em: http://www.ie.ufrj.br/aparte/pdfs/notametodologi ca_familiasconviventes.pdf

18. Sousa IDD. A família na construção da personalidade. New York: Shvoong; 2007. [acesso 09 jun 2008]. Disponível em: http://pt.shvoong.com/social-sciences/l 725783 -familia-naconstru\%C3\%A7\%C3\%A3o-da-personalidade/

19. Trentini M, Silva SH, Valle ML. Enfrentamento de situações adversas e favoráveis por pessoas idosas em condições crônicas de saúde. Rev Latino-am Enfermagem 2005; 13(1): 38-45.

20. Carvalho FT, Morais NA, Koller, SH, Piaccinini A. Fatores de proteção relacionados à promoção de resiliência em pessoas Que vivem com HIV/AIDS. Cad Saúde Pública 2007; 23(9): 2023-33.

21. Senna DM, Antunes EH. Abordagem da família (a criança, o adolescente, o adulto e o idoso no contexto da família). In: Ministério da Saúde (BR). Instituto para o Desenvolvimento da Saúde. Universidade de São Paulo. Manual de condutas médicas. São Paulo: IDS; 2001 . 
Apêndice A

Genograma Família 4

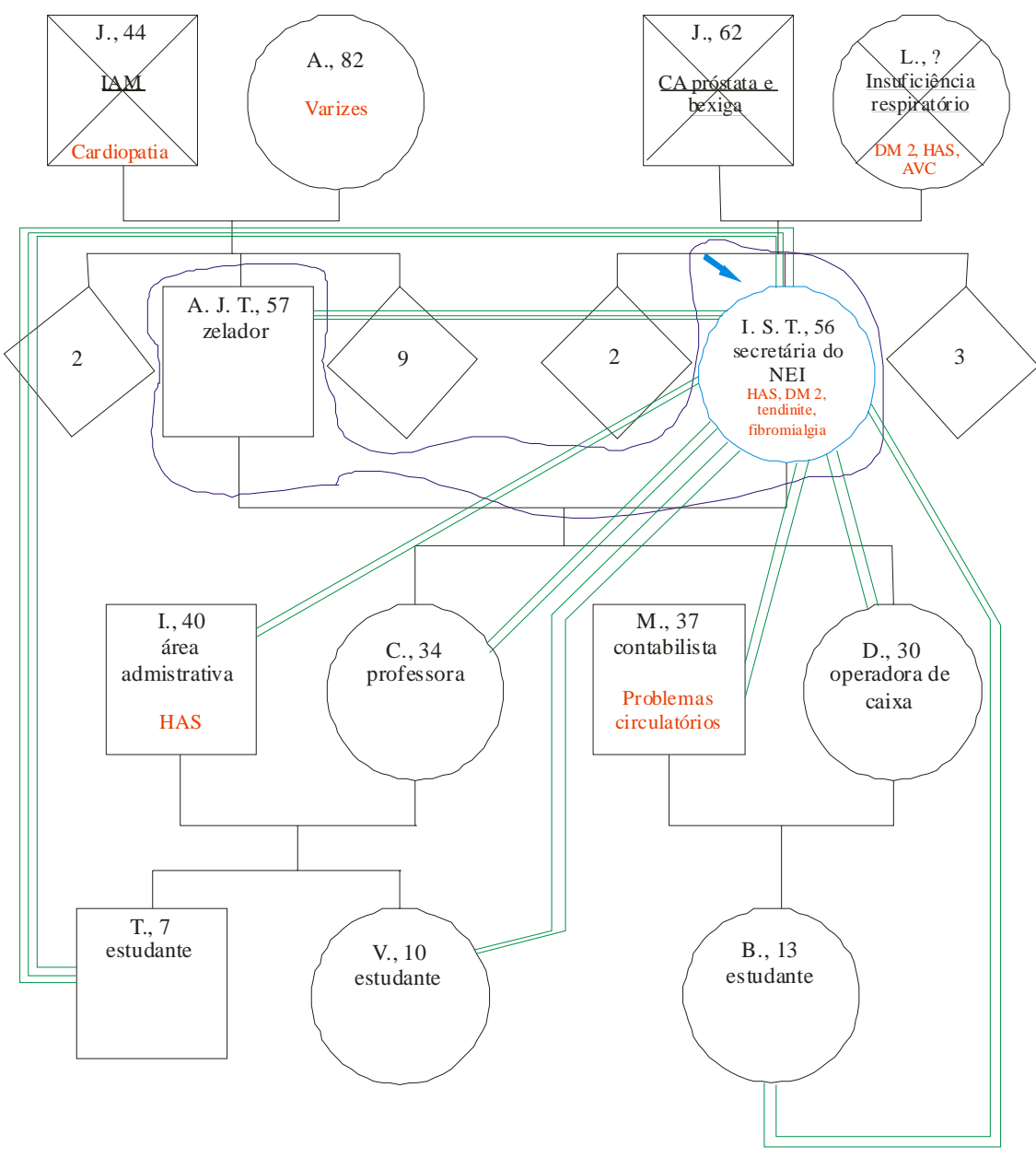

Legenda

pessoa índice
sexo masculino


Pereira APS, et al.

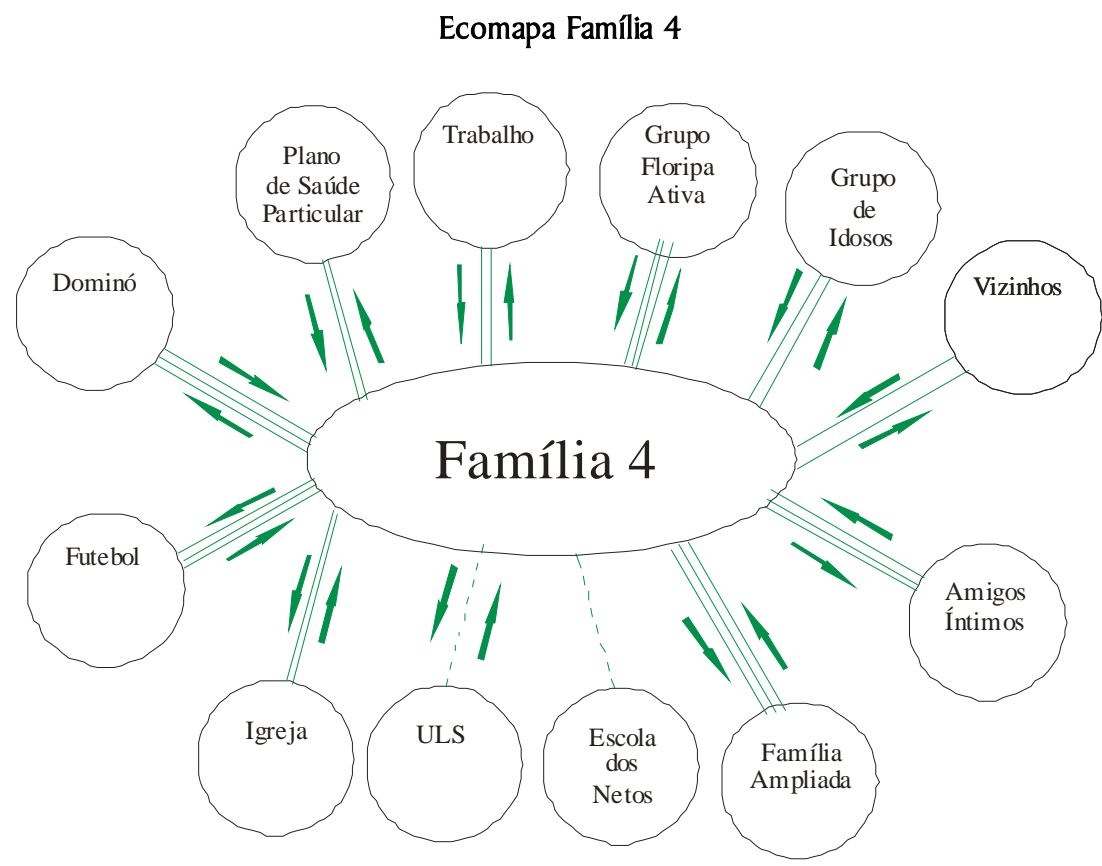

Legenda
relações muito próximas
relações conflituosas
energia e fluxo de recursos
relacionamentos distante
ausência de relações 


\section{Apêndice B}

\section{Genograma Família 6}

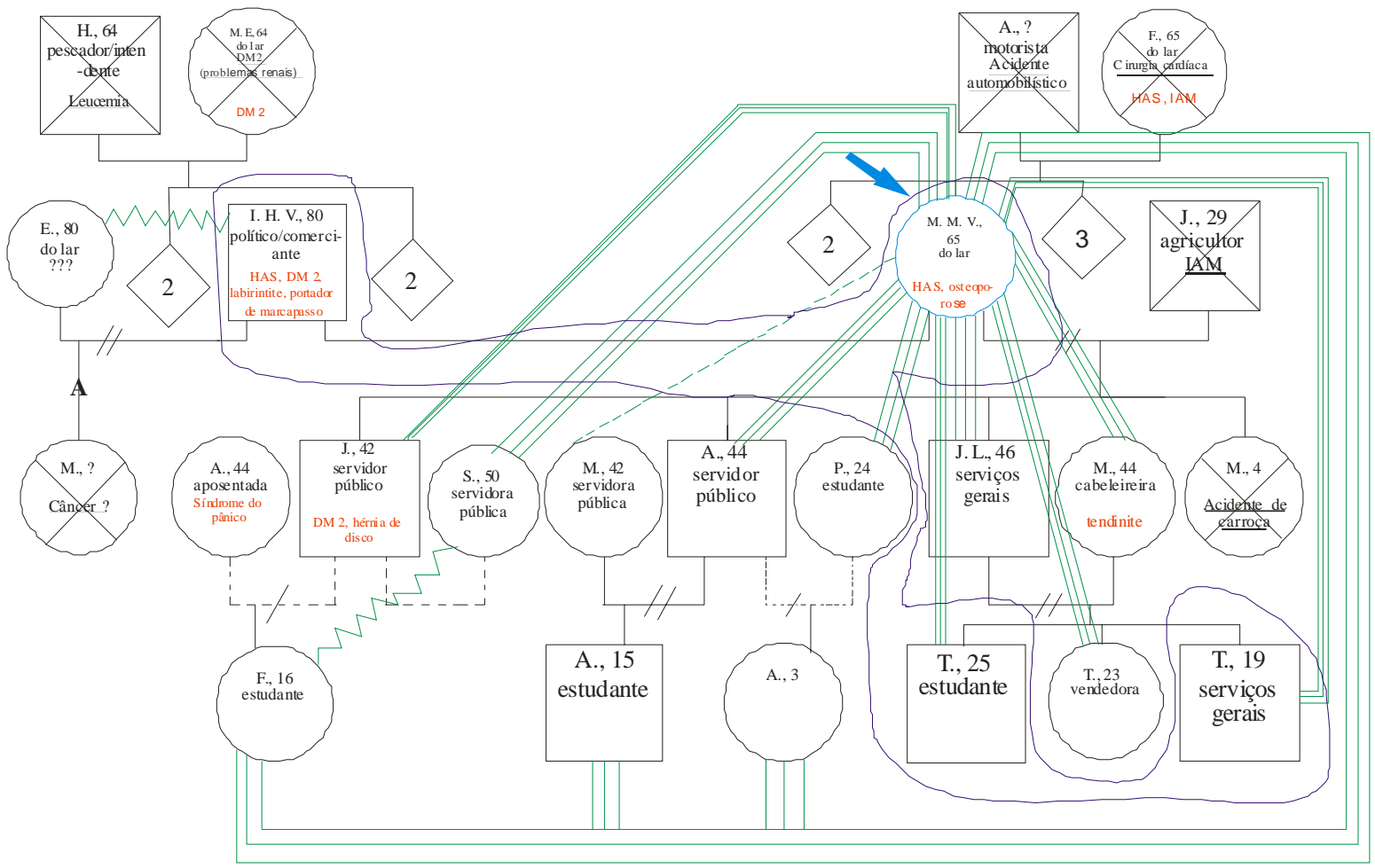

Legenda

pessoa índice
sexo masculino feminino


Pereira APS, et al.

Ecomapa Família 6

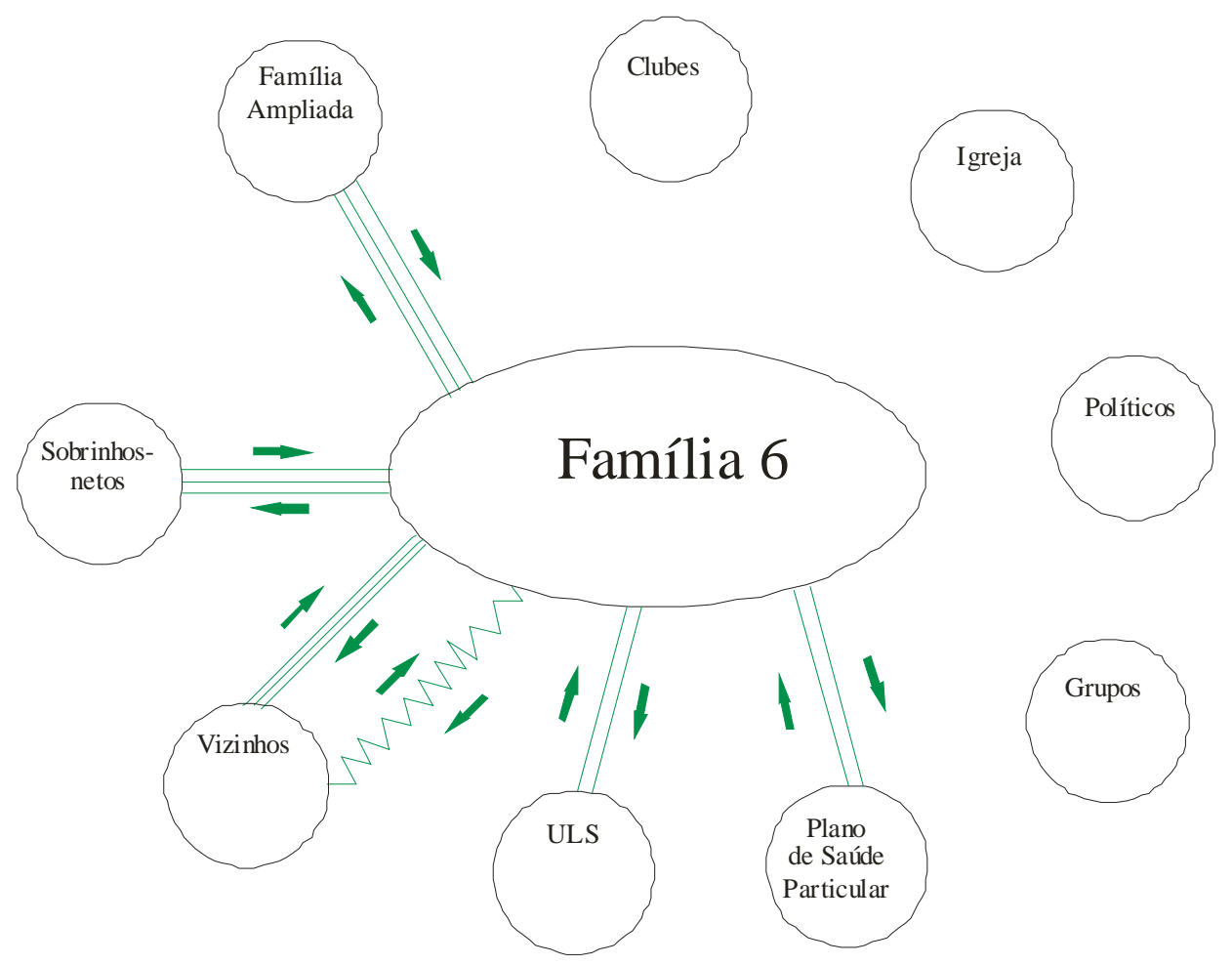

Legenda

relações muito próximas

relações conflituosas $\longrightarrow$ energia e fluxo de recursos

relacionamentos distantes ausência de relações 